\title{
Low Level Laser Therapy in the Treatment of Temporomandibular Joint Arthritis: Questions and Answers
}

\author{
Marini Ida and Gatto Maria Rosaria \\ Department of Oral Sciences, School of Dentistry, "Alma Mater Studiorum", \\ University of Bologna \\ Italy
}

\section{Introduction}

Temporomandibular disorder (TMD) is a collective term for a number of clinical signs and symptoms involving masticatory muscles, temporomandibular joint (TMJ) and associated structures (De Leeuw, 2008)

Some studies show that $3-7 \%$ of the adult population seek care for TMJ pain and dysfunction (Carlsson, 1999) and the range of symptom occurrence to be between 16\%and $59 \%$ and the range of clinical signs to be between $33 \%$ and $86 \%$. Among individuals with TMJ disorders $11 \%$ had symptoms of TMJ arthritis. (Mejersjo \& Hollender, 1984; Tanaka, Detamore et al., 2008) There is disagreement between the classification of degenerative joint disease as presented by the American Association of Orofacial Pain and the RCD/TMD( Research Diagnostic Criteria of Temporomandibular Disorders) (LeResche, 1997)

\subsection{Anatomy of TMJ}

Before we start discussing TMD treatments, it is important to review anatomy.

Is the TMJ similar to other synovial joints in the human body?

No. TMJ is the only synovial joint whose surface is not covered with hyaline cartilage but with fibrocartilage. One more difference is the fact that in the TMJ teeth are present as an intermediate structure (Schwartz \& Marbach, 1965). The masticatory system is dynamic, not static, and it continuously changes due to the abrasion of dental surfaces

\section{Position of the TMJ}

Typically, the mandible has been considered to be connected to the skull by means of two synergically acting joints: the right and left TMJs. Both these joints are condylar synovial joints (diarthroses) that enable the characteristic anterior displacement (Testut, 1971).

Because of this displacement, the TMJ has been regarded to as an atypical joint.

\section{Composition of the TMJ}

The TMJ is a ginglymoarthrodial synovial joint. The joint is encapsulated and immersed in synovial fluid, and is stress bearing and capable of both rotational and translatory movements. The mandibular condyle can move in a variety of directions within the 
mandibular fossa. Condylar movements are protected from direct contact with the bony architecture of the fossa through an intricate system of fibrocartilage and synovial structures. The TMJ is structurally unique, consisting of only two joint in the body with vascularised tissue within the capsular ligament. Since the disc is a vascular and not innervated, pain from within the joint is in all probability due to inflammation or injury of the highly vascularised and innervated retrodiscal tissue or inflammation of the synovial tissues. (Loughner, Miller et al., 1997)

\section{Movement of the TMJ}

When the TMJ is in motion, the interarticular disc is always positioned between the fossa/eminence and condyle by the action of the superior lateral pterygoid muscle and the uppermost elastic portion of the posterior attachment known as the postero-superior retrodiscal lamina of the retrodiscal tissue. During function, the lateral and medial discal collateral ligaments attach the disc to the condyle on the inferior surface of the disc (fig. 1).
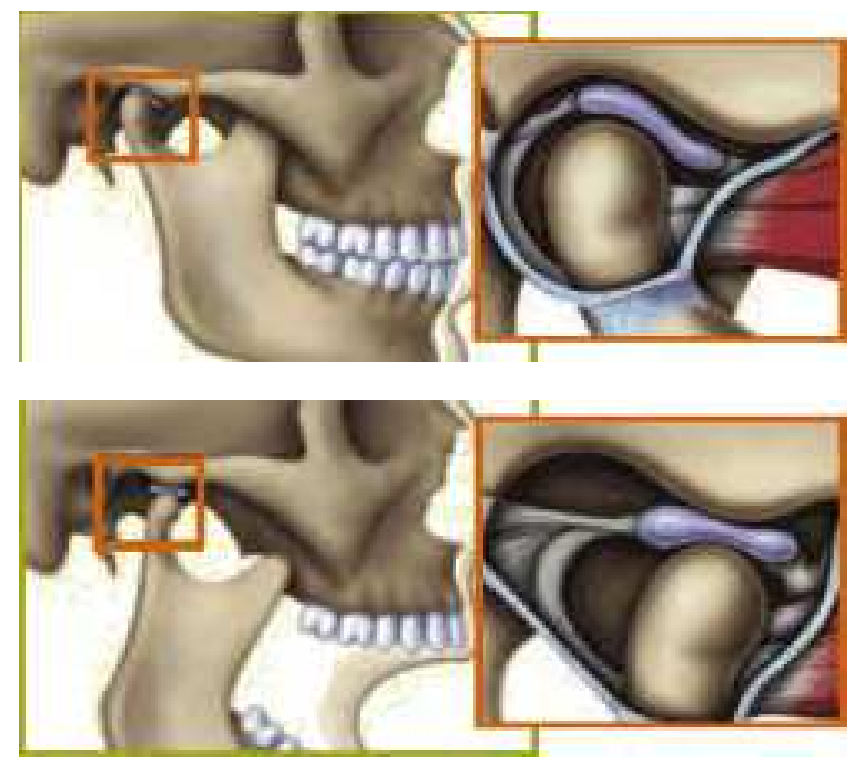

Fig. 1. Functional anatomy of TMJ.

The superior surface of the disc translates or slides along the posterior aspect of the articular eminence during full mouth opening. Translation of the condyle occurs as a result of the action of the inferior lateral pterygoid muscle, which protrudes from the mandible, in concert with other mandibular depressors the infra- and suprahyoid musculature. The posterosuperior retrodiscal lamina acts passively to pull the disc posteriorly during opening as the condyle translates anteriorly. The superior lateral pterygoid muscle contracts eccentrically during closure, stabilizing the disc against the distal slope of the articular eminence. (Laskin, 1994) The two synovial membrane layers line the joint capsule and disc, except on the articulating surface, and produce synovial fluid, fulfilling the nutritional needs of the joint. (Dijkgraaf, de Bont et al., 1996) 


\section{Composition of the synovial fluid}

The joint space is filled by the highly viscous synovial fluid, containing hyaluronic acid and glycoprotein lubricant. Hyaluronic acid is a polymer of D-glucuronic acid and D-Nacetylglucosamine, which is highly unstable and degrades in the presence of inflammation.( Nitzan, Nitzan et al., 2001)

In synovial joints is shared by the articular cartilage, the subchondral bone, and the disc. In synovial joints the subchondral bone shares loading with articular cartilage. Only 1-3\% of load forces are attenuated by cartilage while the normal subchondral bone is able to attenuate about $30 \%$ of the load through the joints.(Imhof, Sulzbacher et al., 2000) The subchondral bone protects the articlar cartilage from damage caused by excessive loading. The condylar ear and the articular fossa receive their blood supply from arteries supplying the underlying bone. In the TMJ, the disc, through its viscoelastic properties, functions as a stress absorber and stress distributor. It contributes to prevent stress concentration and excessive stress in the cartilage and bone components of the joint, thus protecting the joint. (Tanaka \& van Eijden, 2003) Articular surface remodelling potential persists having the proliferative layer in the articular cartilage that can resume the proliferative activity if the occasion demands.

\section{Blood supply to the TMJ}

The articulating surfaces are free of blood vessels, but the synovial membrane is usually well supplied with minute vessels. The most significant blood supply enters the posterior aspect of the joint through the retrodiscal pad. A less significant quantity of the blood supply to this plexus comes from vessels within the mandible or temporal bone, which enter the joint at the peripheral attachment of the joint capsule. (Charles, Boyer et al., 1964)

\section{Initiating events in TMJ arthritis}

The term arthritis refers to an inflammatory condition affecting an articulation that results in erosion and fibrillation of articular cartilage and degeneration of adjacent sub-condral bone. Over recent years the term arthritis has evolved to distinguish a non inflammatory condition producing similar degenerative changes.

\section{Initiation of TMJ OA}

Wilkes (Wilkes, 1989) has suggested that TMJ arthritis is the last stage in the process of TMJ internal derangement, to explain the process is that as a result of joint intrinsic or extrinsic overloading, the lubrication system is compromised, the disc lags behind, and the condyle is pulled forward, away from the lagging disc. The normally firm attachment of the disc to the condyle becomes loose. The loose disc does not stay in its normal position but falls, usually anteriorly, starting the process of disc displacement (Nitzan, 2001) When the retrodiscal area is inadaptable, it perforates on loading, thus leading to arthritis. Conversely, it has been suggested that TMJ arthritis may precede disc displacement (de Bont, Boering et al., 1986) Joint degeneration is associated with disintegration of the joint constituents. Many studies have shown arthritis changes prior to disc displacement. (de Bont \& Stegenga, 1993)

\section{Is arthritis a reparative or a disruptive process?}

Arthritis is a reparative process in the first place, with the purpose of recovering joint cartilage lesions. 
When the loading is controlled, the retrodiscal area is adaptable and becomes disk-like (Manfredini, 2010)

This process of compensation unfortunately fails most of the times and a degradation takes place, which leads to losing normal functions in the affected joints. Early signs of TMJ arthritis are cellular proliferation and increased condrocytes metabolic activity. Said phenomena, when observed with SEM, present with a very developed wrinkled endoplasmatic reticle, a luxuriant Golgi apparatus and numerous secretory vescicles (de Bont \& Liem, 1985). That leads to active reparative processes so that arthritis can remain asymptomatic for years. Next, an increase in the cartilage volume is observed, caused by a higher water absorption, and the cartilage surface becomes irregular (de Bont, Liem et al., 1985).

Condrocytes multiply and present with an increased metabolic activity. Collagene begins to lose its organization presumably following the liberation of proteolitic enzymes (de Bont \& Liem, 1985).

After that follows a phase in which TMJ presents at first with deep surface cracks and then with progressive loss of the cartilage due to mechanical abrasion (de Bont , Liem et al., 1985).

In this phase proliferated condrocytes can be observed next to the deeper cracks of the cartilage (de Bont, Boering et al., 1986).

At a final stage, cracks in the cartilage appear more and more deep and the cartilage gradually disappears as a consequence of total destruction of collagene and proteoglycans.

The last condrocytes die and the underlining bone becomes exposed.

TMJ arthritis is clinically present with clicks and, less often, with limited mobility of the mandible.

These descriptions, as observed with optical microscopy and SEM, are perfectly coincident with clinical and histological findings in great joints. Although enzymatic processes have not been studied in the TMJ, it can be thought that an analogy exists with the mechanisms described in this chapter.

\section{Is TMJ arthritis a rare event?}

It is not a rare event. It is not typical of the adult age and it can present in both adults and young subjects.

\subsection{Local and systemic risk factors of arthritis}

The TMJ function will remain normal as long as its adaptive capacity is not compromised. The changes in the joint associated with the adaptation process are considered as asymptomatic arthritis. The failure of the joint to adjust may cause symptoms such as pain and/or limitation depending on the presence of risk factors, thus confirming the cyclic nature of arthritis. Local and systemic risk factors (micro- and macro-trauma, parafunction, joint laxity, abnormal alignment, occlusal changes etc.) may results in overloading and/or immobilization, thus jeopardizing TMJ integrity.

\section{Which are the risks factors of TMJ overloading?}

Causes that lead to loading of the joint include clenching, occlusal changes (eg premature contact, teeth extractions, posterior bite collapse, teeth inclination) etc. These may set off abnormal compressive and shear forces.

On the other hand, it has an intra-articular origin, eg inflammation, infection, and hemarthritis, in which there is an increase in intra-articular pressure that consequently increases the joint loading. 
Macro-trauma such as whiplash, for example, involves both extrinsic and intrinsic joint overloading. By stretching the joint ligaments, the joint's stability to withstand extrinsic loading is affected, and the initiation of an inflammatory reaction within the joint increases the intrinsic loading (Manfredini, 2010). Abnormal alignment, joint laxity, and disc displacement all decrease the joint's ability to cope with increased joint loading.

\section{Which are the risks factors of TMJ immobilization?}

TMJ immobilization is considered to be one of the principal causes of joint deterioration, mainly due to inability of the body to eliminate the harmful effects of inflammation. Immobilization might be caused by extrinsic or intrinsic factors and rehabilitation is possible only when the correct diagnosis is made. Extrinsic or extra-articular causes included myofascial pain disorder, extra-articular infection, coronoid hyperplasia, or other pathologies. Intra-articular inflammatory perfusion, infection, and hemarthritis are all intrinsic causes of immobilization. Advancing age, sex, hormonal factors, genetics, nutrition, obesity, and systemic illnesses such as atherosclerosis, diabetes, or osteoporosis may affect the host's adaptive capacity. These factors may contribute to dysfunctional remodelling of the TMJ, even when the biomechanical stresses are within a normal physiologic range. (Laskin , 1994; Arnett, Miliam , Miliam et al., 1996)

\section{TMJ diagnosis}

TMJ arthritis is a disorder represented by variable combinations of signs and symptoms including pain, limitation in movements, joint noises, malocclusion etc that may be uncovered by means of several type of examination.

\section{The TMJ diagnosis}

\subsection{Clinical extraoral and intraoral examination}

Pain may not necessarily be present, when it occurs, it might be severe and localized to the joint. Mouth opening may not be limited or may present limitation originating in the affected joint. Noise such as cliking and or crepitus may or may not be present. Lateral movements, protrusive mandibular movements, existence of deviation, and the exact location of pain during each movement are considered. Intraorally, occlusal findings, such as deviation of dental midline, crossbites, ipsi or controlateral open bite, missing teeth, and posterior bite collapse are recorded.

Auscultation for joint noises (cliking, crepitus) and eliciting pain on palpation of TMJ, head and neck muscles are recommended.

\subsection{Imaging}

Imaging has played an important role in the diagnosis of TMJ arthritis, however there is only a limited correlation between clinical and radiographic findings. Severe symptoms may be associated with imaging changes or, alternatively severe changes on radiographs may be associated with an asymptomatic joint.

For radiologic evaluation panoramic radiographs can be obtained for initial screening purposes. Computed tomography (CT) provides a three dimensional view of the morphologic changes in the TMJ and bone mineral density in the mandibular condyle. Imaging of an osteoarthritic joint in the advanced stages typically shows erosion of the 
cortical outline, osteophytes, subcortical cysts, reduced joint space, and the presence of condylar deformities and osteophytes (Fig. 2, 3).

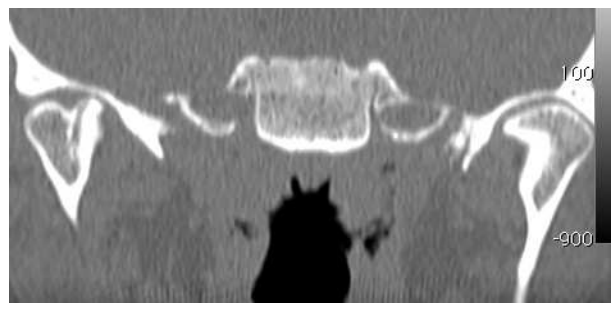

Fig. 2. CT of TMJ arthritis (coronal section)

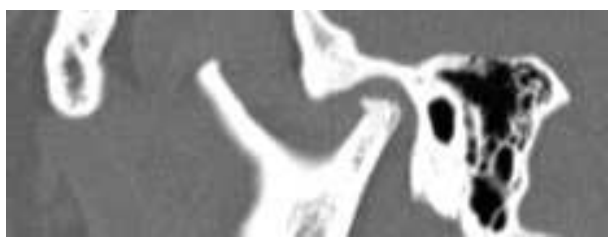

Fig. 3. CT of TMJ arthritis (sagittal section)

MRI imaging shows TMJ soft tissue abnormalities such as disc displacement, join perfusion and bone marrow signal changes related to TMJ arthritis (fig. 4).

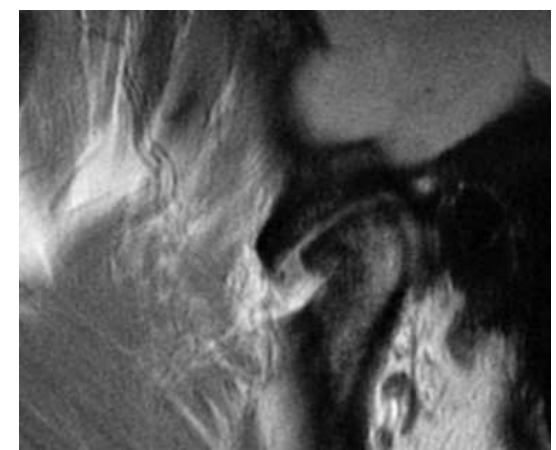

Fig. 4. MRI of TMJ arthritis (sagittal section)

\section{Treatment of TMJ arthritis}

A correct evaluation of the patient is the key for appropriate treatment. The prognosis of arthritis following conservative management has been shown to be good and stable. Although, radiologically, bone may show deterioration, clinical sign and symptoms tend to improve.

Treatment, in general, should address the rehabilitation of the joint defence mechanisms such as blood supply, movements, shock absorbance, and remodelling potential by coping with the patient's risk factors. 


\subsection{Non surgical treatment}

A large variety of non-steroidal anti-inflammatory drugs (NSAIDs) can be used to reduce TMJ inflammation and the associated pain. They should be used at an early stage before any other treatment. However, they are not a long-term remedy for TMJ arthritis.

\subsubsection{Local treatments}

\section{Physical therapy for the TMJ}

Reduced mandibular mobility is caused by intra-articular restriction or by muscular dysfunction, physical exercises are beneficial to prevent formation of intra-articular adhesions and to increase the blood flow and strength of the jaw muscles. Physical therapy is a valuable adjunct to other treatments for TMJ arthritis aimed at normalizing the functional capability of temporomandibular system

In difficult cases or when cooperation is not achieved, it is the physician's responsibility to refer the patient to a professional physical therapist; exercises include passive and active symmetric movements in all directions, further stretching on maximal movement exercises, as well as movements against resistence.

\subsubsection{Acupuncture}

Acupuncture has been used as an adjunct to other therapy for pain relief in patients with OA. Furthermore, acupuncture has not effect on joint pain and tenderness or on the acute phase reactants and disease activity (Casimiro ,Barnsley et al., 2004).

\section{Iontophoresis and Phonophoresi}

Iontophoresis and Phonophoresi are techniques to enhance the transport of drug ions across a tissue barrier. The effects of iontophoretically-applied dexamethasone in combination with lidocaine were evaluated in patients with painful TMJ disc displacement, with or without reduction and in patients with $\mathrm{OA}$. Iontophoretically-applied dexamethasone was effective in improving mandibular function, mobility but not in reducing pain.

\subsubsection{Bite appliances}

Muscular hyperfunction or occlusal trauma can be a primary cause of OA, and these factors might also be detrimental and accelerate tissue destruction in the case of systemic inflammatory joint disease involving the TMJ. Treatment with occlusal bite appliances has been advocated mainly in patients with pain of muscular origin due to muscle hyperfunction or tension (Major \& Nebbe, 1997; Ekberg, Vallon et al., 2003).

But there is no evidence of the efficacy of treating TMJ OA with occlusal appliance (Al -Ani , Davies et al., 2004).

\subsubsection{Low-level laser therapy}

Superpulsed low-level laser therapy (LLLT) seems to be a good choice as a non-invasive treatment for tempomandibular joint pain while exhibiting a low cost for the patient. Many authors have reported significant pain reduction with low-level laser therapy in acute and chronic musculoskeletal pain conditions (Bjordal, Couppè et al., 2003; Ninomiya, Hosoya et al., 2007).

The results of many works show no statistical improvements for any of following: localized swelling, muscle strength, functional status, or global assessments with laser treatment. The 
major limitation of the systematic meta-analyses about LLLT is the heterogeneity of clinical application, including different dosages, wavelengths and types of LLLT.

Which are the evidence-based proves of the efficacy of LLLT in the treatment of TMJ ARTHRITIS?

Our superiority randomized double-blind clinical trial in parallel arms was carried out with the aim to investigate the efficacy of the new superpulsed low-level laser therapy versus anti-inflammatory and placebo therapy in the treatment of TMD, and to determine the optimal time and exposure application to LLLT for treating arthritis with pain. (Marini, Gatto et al., 2010)

\section{How was the trial designed?}

A total of 99 patients with temporomandibular joint disorders, secondary to disc displacement without reduction (Fig. 5) or arthritis with articular effusion (Fig. 6) were randomly divided into 3 groups. Thirty-nine patients received LLLT in 10 sessions over 2 weeks, 30 patients received ibuprofen $800 \mathrm{mg}$ twice a day for 10 days, and 30 patients received sham laser as placebo in 10 sessions over 2 weeks. Pain intensity was measured by visual analogue scale at baseline, 2, 5, 10, and 15 days of treatment. Mandibular function was evaluated by monitoring active and passive mouth openings and right and left lateral motions at baseline, 15 days, and 1 month of treatment. Magnetic resonance imaging was performed at baseline and the end of therapy.

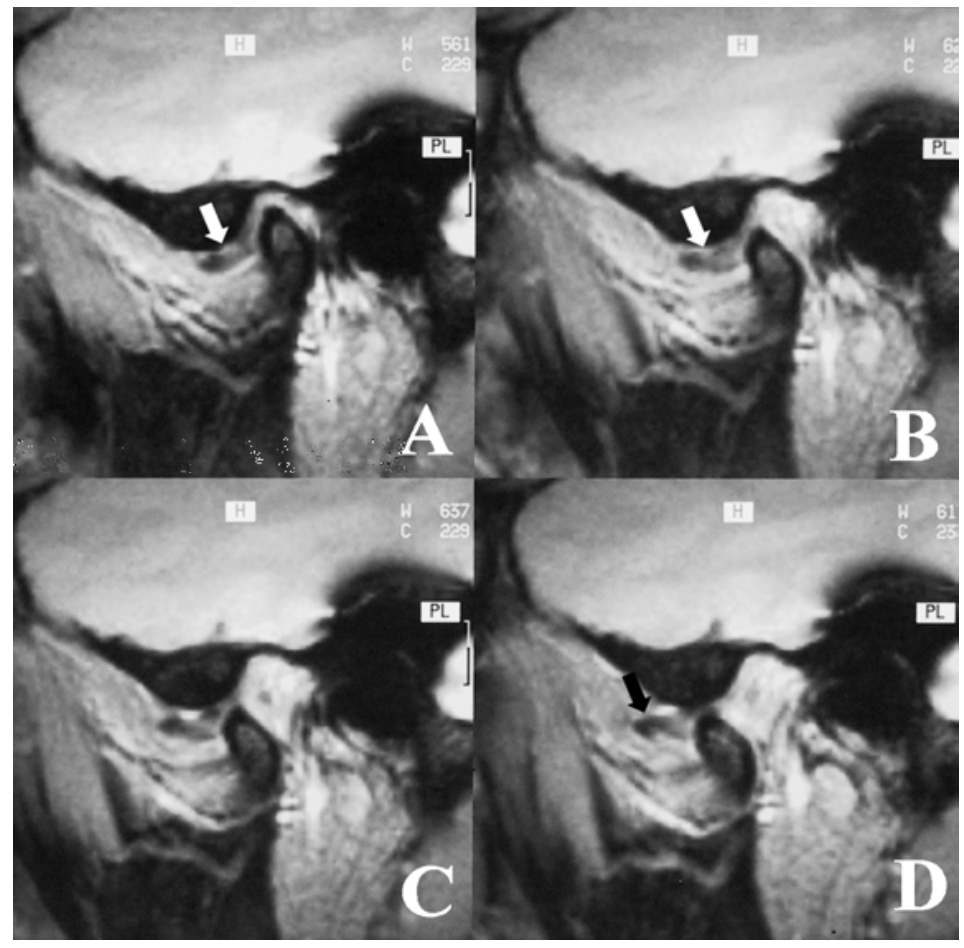

Fig. 5. MRI of TMJ disc displacement without reduction 


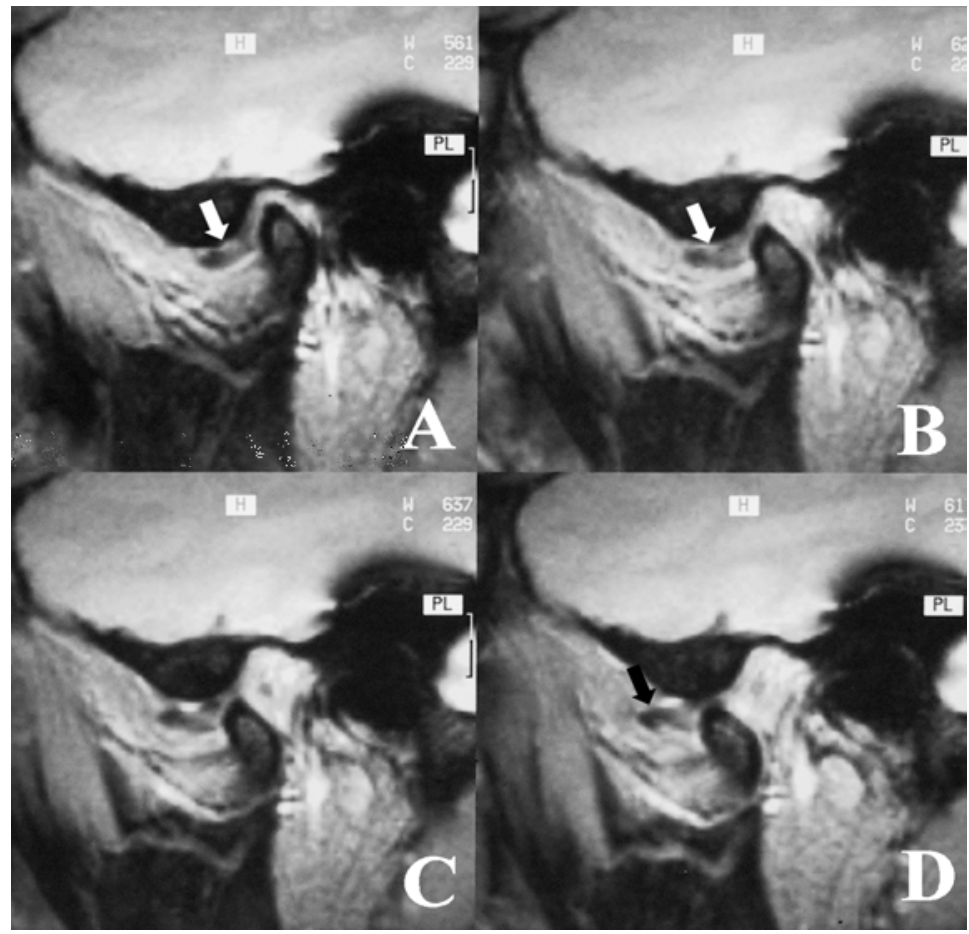

Fig. 6. MRI of TMJ arthritis with articular effusion (sagittal section)

\section{Which were the results?}

Mean visual analogue scale pain scores in LLLT group was significantly lower than in nonsteroidal anti-inflammatory drug group and control group $(\mathrm{P}=0.0001)$ from fifth day up to the end of the observation period. As for active and passive mouth openings and right and left lateral motions, superiority of LLLT was evident 1 month after treatment (interaction time treatment, $\mathrm{P}=0.0001$ ).

Therefore mandibular function improved in all LLLT patients proving the effectiveness in the treatment of pain, as demonstrated by a significant improvement in clinical signs and symptoms of temporomandibular joint disc displacement without reduction and arthritis at the end of treatment and stability over a period of 1 month.

\section{Which were doses and times of LLLT?}

Each patient received laser therapy, gallium-arsenide diode superpulsed laser, (LUMIX 2 HFPL Fisioline, Verduno, Italy) with time pulsation<200 ns; frequency range 1 to $50 \mathrm{kHz}$, wave length $910 \mathrm{~nm}$, mean power $400 \mathrm{~mW}$, and peak power $45 \mathrm{~W}$. The affected TMJ areas of these patients were treated daily in 3 steps:

1. $20 \mathrm{kHz}$ for 10 minutes

2. $18 \mathrm{kHz}$ for 5 minutes

3. $16 \mathrm{kHz}$ for 5 minutes

All patients were treated for 10 consecutive days ( $5 \mathrm{~d} / \mathrm{wk})$ in right and left TMJ,. Laser test was performed at the end of every application to measure the laser output. The laser 
parameters selected were based pragmatically on those used in everyday practice by a principal author, which had been formally piloted in previous studies. (Marini , Scala et al., 2003)

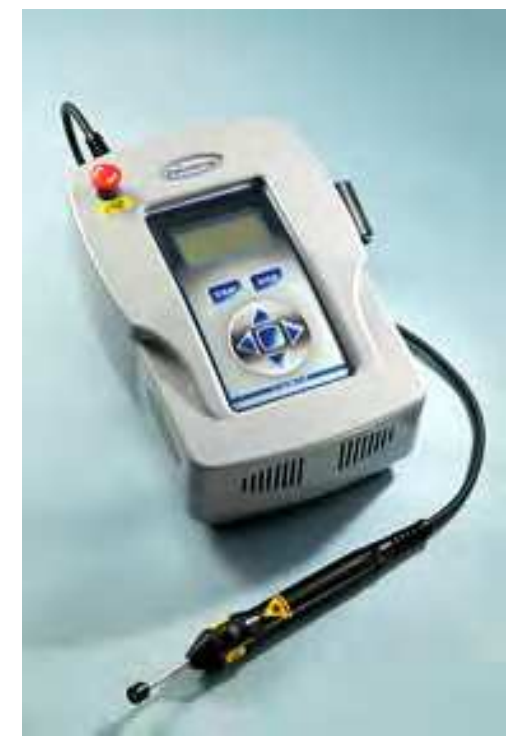

Fig. 7. Low-Level Laser device.

Which were the main differences between LLLT and NSAIDs treatment, observed in our study?

The laser group showed an increase in pain, which then disappeared for a long time; the increased pain could be explained with an increased local hyperemia.

Patients treated with NSAIDs showed an improvement in pain and mandibular function during the time of treatment but returned to more or less the same level as pretreatment conditions after treatment terminated. It is hard to compare our outcomes with those of other studies that obtained similar results despite differences in design, dosage, intensity, and frequency. In Italy, administration of NSAIDs is suggested for not more than 7 to 10 days, except for rheumatoid arthritis, whereas in many countries this therapy can be prolonged from 4 to 6 weeks.

Real hazards of long-term administration of NSAIDs have been recognized lately as involving renal disease and serious toxicity to the gastrointestinal tract, as well as increasing the risks of adverse cardiovascular events. A comprehensive review of the primary literature reveals modest scientific support for the assertion that the daily use of NSAIDs offers benefits for patients with chronic TMD pain. (List , Axellson et al., 2003)

Does laser treatment influence active and passive mouth opening and right and left lateral motion?

These parameters are always significantly different between patients treated with laser and patients treated with NSAIDs (Table 1 and 2). Superiority of laser is mostly evident one month after treatment (interaction time-treatment $p=0.0001$ ) 
Active mouth opening Passive mouth opening

\begin{tabular}{|l|c|c|c|c|c|c|}
\hline Comparison & \multicolumn{3}{|c|}{ p-values at } & \multicolumn{3}{c|}{ p-values at } \\
\hline $\begin{array}{l}\text { Laser vs } \\
\text { NSAIDs }\end{array}$ & 0.001 & 0.001 & 0.001 & 0.001 & 0.001 & 0.001 \\
\hline $\begin{array}{l}\text { Laser vs } \\
\text { Control }\end{array}$ & 0.031 & 0.001 & 0.001 & 0.012 & 0.001 & 0.001 \\
\hline $\begin{array}{l}\text { NSAIDs vs } \\
\text { Control }\end{array}$ & 0.026 & 0.083 & 0.003 & 0.041 & 0.069 & 0.001 \\
\hline
\end{tabular}

(1) Marini, Ida MD, DDS; Gatto, Maria Rosaria PhD; Bonetti, Giulio Alessandri MD, DDS* Effects of Superpulsed Low-level Laser Therapy on Temporomandibular Joint Pain The Clinical Journal of Pain Issue: Volume 26(7), September 2010, pp 611-616 (http:/ / lww.com)

Table 1. Comparisons of the difference of active and passive mouth opening, right and left lateral motion between the groups . $\alpha=0.02$

Right lateral motion

Left lateral motion

\begin{tabular}{|l|c|c|c|c|c|c|}
\hline Comparison & \multicolumn{3}{|c|}{ p-values at } & \multicolumn{3}{c|}{$\begin{array}{c}\text { p-values at } \\
\text { Baseline 15 days 1 month }\end{array}$} \\
\hline $\begin{array}{l}\text { Laser vs } \\
\text { NSAIDs }\end{array}$ & 0.013 & 0.001 & 0.001 & 0.001 & 0.001 & 0.0010 \\
\hline $\begin{array}{l}\text { Laser vs } \\
\text { Control }\end{array}$ & 0.683 & 0.228 & 0.001 & 0.631 & 0.001 & 0.001 \\
\hline $\begin{array}{l}\text { NSAIDs vs } \\
\text { Control }\end{array}$ & 0.296 & 0.232 & 0.741 & 0.411 & 0.123 & 0.412 \\
\hline
\end{tabular}

$(1) \mathrm{a}=0.02$

Table 2. Comparisons of the difference of right and left lateral motion between the groups.

Does time influence active and passive mouth opening and right and left lateral motion in patients treated with laser and patients treated with NSAIDs?

Mean values of these parameters remain stable across the times (Table 3).

\begin{tabular}{|c|c|c|c|}
\hline & Baseline & After treatment & $\begin{array}{l}1 \text { month after } \\
\text { treatment }\end{array}$ \\
\hline \multirow{3}{*}{$\begin{array}{l}\text { Active mouth } \\
\text { opening }(\mathrm{mm})\end{array}$} & L 36,28 \pm 3.44 & L $43.24 \pm 2.71$ & L $45.89 \pm 2.13$ \\
\hline & A $39.85 \pm 2.89$ & A $41,27 \pm 2.49$ & A $40.90 \pm 3.37$ \\
\hline & C $38.06 \pm 3.19$ & C $39.77 \pm 3.96$ & C $37.46 \pm 4.94$ \\
\hline \multirow{3}{*}{$\begin{array}{l}\text { Passive mouth } \\
\text { opening (mm) }\end{array}$} & L $37.97 \pm 3.22$ & L $45.28 \pm 2.37$ & L $47.22 \pm 2.31$ \\
\hline & A $41.68 \pm 3.01$ & A $42.43 \pm 2.77$ & A $42.54 \pm 2.20$ \\
\hline & C $40.00 \pm 3.21$ & C $40.77 \pm 4.06$ & C $38.28 \pm 4.67$ \\
\hline \multirow{3}{*}{$\begin{array}{l}\text { Right lateral } \\
\text { motion }(\mathrm{mm})\end{array}$} & $\mathrm{L} 6,37 \pm 1.08$ & L $8.54 \pm 1.41$ & L $12.20 \pm 1.08$ \\
\hline & A $7.10 \pm 1.28$ & A $8.63 \pm 1.97$ & A $8.22 \pm 1.92$ \\
\hline & C $6.57 \pm 2.43$ & $C 7,98 \pm 2.20$ & C $8.04 \pm 2.26$ \\
\hline \multirow{3}{*}{$\begin{array}{l}\text { Left lateral } \\
\text { Motion }(\mathrm{mm})\end{array}$} & L $6.67 \pm 1.14$ & $\mathrm{~L} 13.01 \pm 1.57$ & L $13.19 \pm 1.54$ \\
\hline & A $6.87 \pm 1.57$ & A $8.82 \pm 1.78$ & A $8.43 \pm 1.97$ \\
\hline & C $6.44 \pm 2.39$ & C $8.01 \pm 2.19$ & C $7.98 \pm 2.21$ \\
\hline
\end{tabular}

Table 3. Active and passive mouth opening, right and left lateral motion at baseline, after treatment and one month after treatment (mean \pm SD) (1) 


\section{May be hypothesized the mechanism of action of LLLT?}

It is interesting to observe that patients examined with MRI at the end of treatment showed a more or less abundant effusion within the intra-articular, which disappeared after laser therapy, whereas it remained stable in the other 2 groups, control and patients treated with NSAIDs. This reabsorption could explain the disappearance of pain through a wash out of the algogenic metabolites and the functional improvement through the elimination of the mechanical obstacle created by the liquid. In the case of arthritis, a series of pathologic phenomenon is present, which results in a synovial inflammation inducing a cascade of reactions and, in particular, prostaglandins and leukotrienes. LLLT might act on the synovia and stimulate cellular energy processes that appear. It could be hypothesized that in the condyle-meniscus coordination a synovitis could arise, even without the evident signs of arthritis, which could result in arthritis as indicated by an author (Stegenga , de Bont et al., 1991)

\section{Which are the main advantages in using LLLT?}

Our therapeutic protocol and the characteristics of LLLT (highest peak power for a few seconds) are suggested in the treatment of painful TMD. An important adjunctive factor is the low cost of the therapy.

\subsection{Surgical treatment}

Surgical procedure is available for the treatment of TMD, ranging from simple arthrocentesis and lavage to more complex open joint surgical procedures.

The general indication for TMJ arthritis surgery is significant TMJ pain and or dysfunction that originates in the joint and worsens during jaw functions, such as talking or clewing on the contralateral side and is refractory to non surgical treatment.

Arthrocentesis and arthroscopy should resolve limited mouth opening, and pain associated with OA .

Condylotomy should be used for high intensity of pain with restriction of opening the mouth. Whereas TMJ surgery should be reserved for advances cases of TMJ arthritis.

\section{References}

Al -Ani MZ, Davies SJ, Gray RJM, Sloan P, Glenny AM. Stabilisation splint therapy for temporomandibular pain disfunction syndrome. The Cochrane Database of Systematic Reviews(website). In: The Cochrane Library, Issue 2, 2004. Oxford, England: Update Software. Available at: http://www.mrw.interscience.wiley.com/cochrane/clysrev/articles/CD002778/fr ame.html. Accessed 16 Sept 2004

Arnett GW, Miliam SB, Gottesman L. Progressive mandibular retrusiom - idiopathic condylar resorption. Part. I. Am J Orthodo Dentofacial Orthop 1996;110:8-15.

Bjordal JM, Couppè C, , Chow RT, et al. A systematic review of low level laser therapy with location- specific doses for pain from chronic joint disorders . Aust J Phisiother. 2003;49:107-116.

Carlsson GE Epidemiology and treatment need for temporomandibular disorders. J Orofac Pain 1999;13:232-237. 
Casimiro L,Barnsley L,Brosseau L, et all.Acupuncture and electroacupuncture for the treatment of RA. The Cochrane Database of Systematic Reviews[ web-site ]In the Cochrane Library, Issue 3,2003.Oxford,England: Update Software.Available at:/ /www.mrw.interscience.wiley.com /Cochrane/ clsysrev/ articles/ CD003788/ frame.html. Accessed 16 Sept 2004

Charles C, Boyer CC, Williams TW, Stevens FH. Blood supply of the temporomandibular joint. J Dent res 1964;43:224-228

de Bont LG, Liem RS, Boering G. Ultrastructure of the articular cartilage of the mandibular condyle: aging and degeneration Oral Surg Med Pathos 1985; 60: 631-641.

de Bont LG, Liem RS, Boering G., et al. Arthritis of the temporamandibular joint: a light microscopic and scannino electron microscopic study of the articular cartilage of the mandibular condyle. J Oral Maxillofac Surg 1985; 43: 481-488

de Bont LG, Boering G, Liem RS, Eulderink F, Westesson P-L. Arthritis and internal derangement of the temporomandibular joint: a light microscopic study. J Oral Maxillofac Surg 1986;44:634-643.

de Bont LG, Stegenga B. Pathology of temporomandibular joint internal derangement and arthritis. Int J Oral Maxillofac Surg 1993;22:71-74.

De Leeuw R,ed Orofacial Pain: guidelines for assessment, diagnosis, and management. $4^{\text {th }}$.ed.Chicago:Quintessence;2008.

Dijkgraaf LC, de Bont LG, Boerning G, Liem RS. Structure of the normal synovial membrane of the temporomandibular joint: a review of the literature. J Oral Maxillofac Surg 1996;64:332-338.

Ekberg E, Vallon D, Nilner M. The efficacy of appliance therapy in patients with temporomandibular disorders of mainly myogenous origin. A randomized, controlled, shortterm trial. J Orofac Pain 2003;17:133-139.

Imhof H, Sulzbacher I, Grampp S, Czerny C, Youssefzadeh S, Kainberger F. Subchondral bone and cartilage disease: a rediscovered functional unit. Invest Radiol 2000;35:581-588.

Laskin DM. Etiology and pathogenesis of internal derangement of the temporomandibular joint: current controversies in surgery for internal derangements of the temporomandibular joint. Oral Maxillofac Surg Clin North Am 1994;6:217.

LeResche L. Epidemiology of temporomandibular disorders: implications for the investigation of etiologic factors. Crit Rev Oral Biol Med 1997;8:291-305.

List T, Axellson S, Leijon G. Pharmacological interventions in the treatment of temporomandibular disorders, atypical facial pain, and burning mouth syndrome. A qualitative systematic review. J Orofac Pain. 2003;17:301-310

Loughner B, Miller J, Broumand V, Cooper B. The development of strains, forces and nociceptor activity in retrodiscal tissues of the temporomandibular joint: current controversies in surgery for internal derangements of the temporomandibular joint of male and female goats. Exp Brain Res 1997;113:311-326.

Major PW, Nebbe B. Use and effectiveness of splint appliance theray: Review of literature. Cranio 1997;15:159-166.

Marini I, Scala A, Russo A, et al. Diode laser therapy is an effective tool for the treatment of temporomandibular joint arthritis. J.Dent Res. 2003;82:C-544 
Marini, Ida MD, DDS; Gatto, Maria Rosaria PhD; Bonetti, Giulio Alessandri MD, DDS* Effects of Superpulsed Low-level Laser Therapy on Temporomandibular Joint Pain The Clinical Journal of Pain Issue: Volume 26(7), September 2010, pp 611-616

Mejersjo C, Hollender L. TMJ pain and dysfunction: relation between clinical and radiofraphic findings in the short and long term. Scand J Dent Res 1984;92:241-248.

Ninomiya T, Hosoya A, Nakaura H, et al. Increase of bone volume by a nanosecond pulsed laser irradiation is caused by decreased osteoclast number and an actived osteoblasts. Bone 2007;40:140-148.

Nitzan DW. The process of lubrication impairment and its involvement temporomandibular joint disc displacement: a theoretical concept. J Oral Maxillofac Surg 2001;59:36-45.

Nitzan DW, Nitzan U, DanP, Yedgar S. The role of hyaluronic acid in protecting surfaceactive phospholipids from lysis by exogenous phospolipase A(2). Rheumatology (Oxford) 2001;40:336-340

Nitzan D,Roisentul Temporomandibular joint arthritis 111-134 in Manfredini D. Current concepts on temporomandibular disorders Quintessence Publishing Co.Ltd print in Germany 2010

Schwartz L, Marbach JJ, Changes in the temporomandibular joints with age. Periodontics 1965; 3: 184-189.

Stegenga B, de Bont LG, Boering G. Tissue response to degenerative changes in the temporomandibular joint: a review. J Oral Maxillofac Surg. 1991;49:1079-1088.

Tanaka E, van Eijden T. Biomechanical behaviour of the temporomandibular joint disc. Crit Rev Oral Biol Med 2003;14:138-150.

Tanaka E, Detamore MS, Mercuri LG. Degenerative disorders of the temporomandibular joint: etiology, diagnosis, and treatment, J Dent Res 2008;87:296-307.

Testut L,Trattato di anatomia V ed., UTET, Torino.1971 Vol 1 .

Wilkes C. Internal derangement of the TMJ. Arch Otolaryngol Head Neck Surg 1989;115469. 


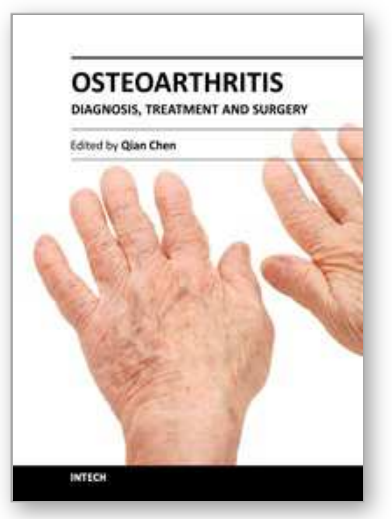

\author{
Osteoarthritis - Diagnosis, Treatment and Surgery \\ Edited by Prof. Qian Chen
}

ISBN 978-953-51-0168-0

Hard cover, 404 pages

Publisher InTech

Published online 02, March, 2012

Published in print edition March, 2012

Osteoarthritis is one of the most debilitating diseases affecting millions of people worldwide. However, there is no FDA approved disease modifying drug specifically for OA. Surgery remains an effective last resort to restore the function of the joints. As the aging populations increase worldwide, the number of OA patients increases dramatically in recent years and is expected to increase in many years to come. This is a book that summarizes recent advance in OA diagnosis, treatment, and surgery. It includes wide ranging topics from the cutting edge gene therapy to alternative medicine. Such multifaceted approaches are necessary to develop novel and effective therapy to cure OA in the future. In this book, different surgical methods are described to restore the function of the joints. In addition, various treatment options are presented, mainly to reduce the pain and enhance the life quality of the OA patients.

\title{
How to reference
}

In order to correctly reference this scholarly work, feel free to copy and paste the following:

Marini Ida and Gatto Maria Rosaria (2012). Low Level Laser Therapy in the Treatment of Temporomandibular Joint Arthritis: Questions and Answers, Osteoarthritis - Diagnosis, Treatment and Surgery, Prof. Qian Chen (Ed.), ISBN: 978-953-51-0168-0, InTech, Available from: http://www.intechopen.com/books/osteoarthritisdiagnosis-treatment-and-surgery/low-level-laser-therapy-in-the-treatment-of-temporomandibular-jointosteoarthritis-questions-and-rep

\section{INTECH}

open science | open minds

\author{
InTech Europe \\ University Campus STeP Ri \\ Slavka Krautzeka 83/A \\ 51000 Rijeka, Croatia \\ Phone: +385 (51) 770447 \\ Fax: +385 (51) 686166 \\ www.intechopen.com
}

\author{
InTech China \\ Unit 405, Office Block, Hotel Equatorial Shanghai \\ No.65, Yan An Road (West), Shanghai, 200040, China \\ 中国上海市延安西路65号上海国际贵都大饭店办公楼405单元 \\ Phone: +86-21-62489820 \\ Fax: +86-21-62489821
}


(C) 2012 The Author(s). Licensee IntechOpen. This is an open access article distributed under the terms of the Creative Commons Attribution 3.0 License, which permits unrestricted use, distribution, and reproduction in any medium, provided the original work is properly cited. 